\title{
The CurRent Issues AND Challenges OF Product Recovery of MAting Surfaces
}

\author{
SINGH, H. \& JAIN, P.K.
}

Abstract: The surface quality and its deviation play a vital role in determining the operational performance of the engineering parts. This is mainly driven by controlled generation of mating surfaces by using appropriate surface material and finishing process. To bring a surface to a desired state of finish or dimensional tolerance during the recovery of the engineering parts specially mating surfaces generally creates many surface integrity issues, e.g. crack generation, internal stresses, thermal damage and pilling of surface etc. This chapter focuses the current issues and challenges of product recovery, with the objective to recover the parts to a desired level of design intricacies with the objectives of saving energy, saving raw materials and to reduce related environmental hazards.

Key words: product recovery, mating surfaces, material deposition, finishing, surface problems
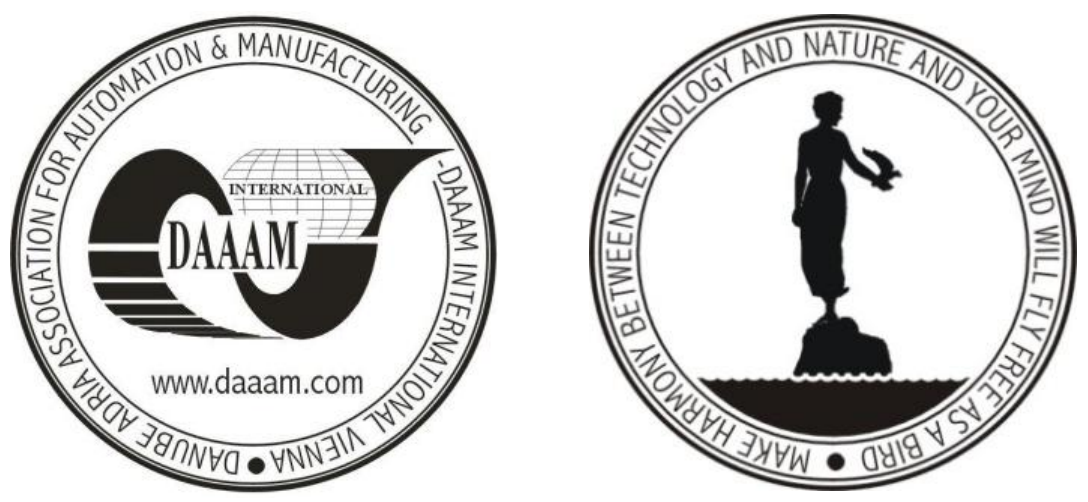

Authors' data: Singh, H[arpreet], Jain, P[ramod] K[umar], Mechanical \& Industrial Engineering Department, Indian Institute of Technology Roorkee, India, hps85@yahoo.in,pjainfme@iitr.ernet.in

This Publication has to be referred as: Singh, $\mathrm{H}$ [arpreet] \& Jain, $\mathrm{P}$ [ramod] K[umar] (2014). The Current Issues and Challenges of Product Recovery of Mating Surfaces, Chapter 29 in DAAAM International Scientific Book 2014, pp.365-372, B. Katalinic (Ed.), Published by DAAAM International, ISBN 978-3-901509-98-8, ISSN 1726-9687, Vienna, Austria

DOI: 10.2507/daaam.scibook.2014.29 
Singh, H. \& Jain, P. K.: The Current Issues and Challenges of Product Recovery of ...

\section{Introduction}

The goal of product recovery is to retain identity and functionality of used products and their components as much as possible, thereby reducing the ultimate quantities of waste. As compared to new products, recovered products cost only $50 \%$ of new products, while $60 \%$ of energy and materials $70 \%$. In addition, $70 \%$ less solid waste generation and $80 \%$ less carbon dioxide emission, which ultimately reduces the environmental impacts (Zhanga et al., 2011).

The traditional approach of many manufactures towards used products has been to ignore them. Manufacturers typically did not feel responsible for what happened with their products after customer use. Most products are considered in such a way that while materials, assembly, and distortion costs were minimized, the repair, reuse and disposal requirements were not taken into account. Manufacturers usually believed that the cost of incorporating these requirements would outweigh the benefits. Most purchasing decisions were made with the intention of minimizing the purchasing costs, instead of optimizing life-cycle performance which includes maintenance, reuse, and disposal issues (Thierry et al., 1995). Consequently, the majority of used products in "developed countries" were land filled or incinerated, with considerable damage to the environment.

Today scenario, there is a rapid increase the consumption of goods thus depleting of resources abruptly. To avoid the danger of unavailability of resources for future generation, it is important for the organizations to think about material recovery. Many companies consider the issues of discarded products a threat to their business. There could be large opportunities for companies that succeed in the ways of embodying current and future environment demands in their business policy. For instance, by offering "green product", companies could attract and retain environmentally conscious customers and employees. Producing greener products could lower future liabilities, insurance rates, and customers disposal costs.

There are five major product recovery approaches: repair, refurbishing, remanufacturing, cannibalization and recycling. These options differ with respect to degree of upgrading. Repair involves the least, and remanufacturing the largest upgrade as new quality. Recycling is a material level approach, reduce the need for raw materials and disposal space, but it involves the use of energy, transportation and processing resources (Lindahl et al., 2006).

A survey of the literature reveals little information on the subject of recovery of mating surfaces. This is mainly owing to the absence of sustained research on this subject. The severe work conditions of engineering parts (e.g. shafts, internal cylinder, gears, engine valves, bearings etc.) requires a stable functional surface. The occurrence of surface deterioration with operating time due to wear, erosion, heat and chemical reactions. As a result, the mating surface of the component is not able to perform properly, and the question arises how to put it back into service, repairing or remanufacturing will immediately be considered or replace with a new one.

Product recovery is proceed with the use of suitable metal deposition technique. There are various methods for metal deposition which includes - submerged arc (SA), shield metal arc (SMA), metal inert gas (MIG), tungsten inert gas (TIG), high 
velocity oxy-fuel (HVOF) and laser cladding. Most of these techniques are well maturing in terms of academic research and technological developments (Ma, 2006). But in case of recovery of mating surfaces, these techniques are unable to fulfil the requirements of strict quality standards. In this chapter, the mating surfaces that can be recovered are of concern. This study aims to collect and integrate the most relevant researches and highlights the current issues and challenges of product recovery of mating surfaces.

\section{History}

In the 1940s or earlier, driven by interest, the USA and UK corporations started recovery of used products, later in 1947 Germany started (Chen \& Liang, 2006). During 1970s, the research began on the recycling of waste products at the institute level. In the 1980s the US officially advocated renovation or regeneration of the waste products, and called it "remanufacturing" while Japanese proposed the concept of "renewable plant technology", In 1992, the Russian scholars proposed the idea to establish "the committee of repair heat treatment technology" to the International Heat Treatment Committee. In 1992, the Russian scholars proposed the idea to establish "the committee of repair heat treatment technology" to the International Heat Treatment Committee (Hua et al., 2009). In the United States, Canada, the European Union and other developed countries, the remanufacturing of used mechanical and electrical products has several decades of development history. From technical standards, production technology, processing equipments, recycling of used products, to the remanufactured product sales and after-sales service, the remanufacturing industry has formed a complete industrial system. The remanufactured product range has covered the auto parts, machine tools, construction machinery, railway equipments, medical equipments, and some electronic products. India is yet to take it up as an organised industrial sector (Zhu, 2006).

The global remanufacturing output had more than one hundred billion dollars in 2005. Remanufacturing industry in the United States was the largest, and its output reached 75 billion dollars. The automotive and construction machinery remanufacturing accounted for more than $2 / 3$, and the output reached about 50 billion dollars. Japan had also strengthened the construction machinery remanufacturing. Till $2008,58 \%$ of the construction machinery remanufacturing was used by the Japanese domestic users, and $34 \%$ were exported to foreign countries. The remaining $8 \%$ sold as accessories after dismantling. Till 2004, Volkswagen had been remanufacturing 7.48 million automobile engines and 2.4 million transmissions. The ratio of the company sold remanufactured engines and accessories to the new machine was 9:1 (Xu et al., 2007). Remanufacturing can not only save a huge social wealth, but also significantly improve the combat effectiveness of the military equipments. The US military absorbs a large number of advanced scientific and technological achievements by remanufacturing, thus improves the tactical and technical performance of existing weapons and equipment. Remanufacturing provides excellent application and test opportunities to these advanced technologies. Improvement of the equipment performance of the US military accompanies with the 
Singh, H. \& Jain, P. K.: The Current Issues and Challenges of Product Recovery of ...

equipment remanufacturing. The remanufacturing project research has attracted the attention of the American policy-making departments. The defence manufacturing industry committee in and after 2010 which belongs to the United States National Research Council, had formulated the framework of the defence industry remanufacturing technology about 2010. It proposed the strategy to achieve the future required manufacturing capabilities, and took performance upgrades, life extension technology and remanufacturing technology of the weapon systems as the important research area in current and future defence manufacturing. The defensive weapons research department of Boston University specializes in cost savings data of remanufacturing products, such as aerospace planes, runner weapons systems and military equipment. Longbow AH-64D is a new kind of helicopter which is the remanufacturing product of AH-64A. After remanufacturing, the battlefield survivability, information exchange ability, and navigate ability of the aircraft increases. AH-64D can attack 4 times target numbers at the same time than the $\mathrm{AH}$ 64A and its survivability increase by 7.2 times than the AH-64A. At present, it has become the strongest and most advanced helicopter on active duty in the United States. Target acquisition capability of the remanufacturing M1A1D tanks increases $70 \%$, shortens the fire time and improves accuracy (Xu et al., 2003).

Up to now the various forms of the material/product recovery have been around for a long time. Automobile, aerospace, electronics and defence sector are the most common examples. The common flow diagram of product recovery options (Thierry, 1995) is shown below, where service, product recovery and waste management options included:

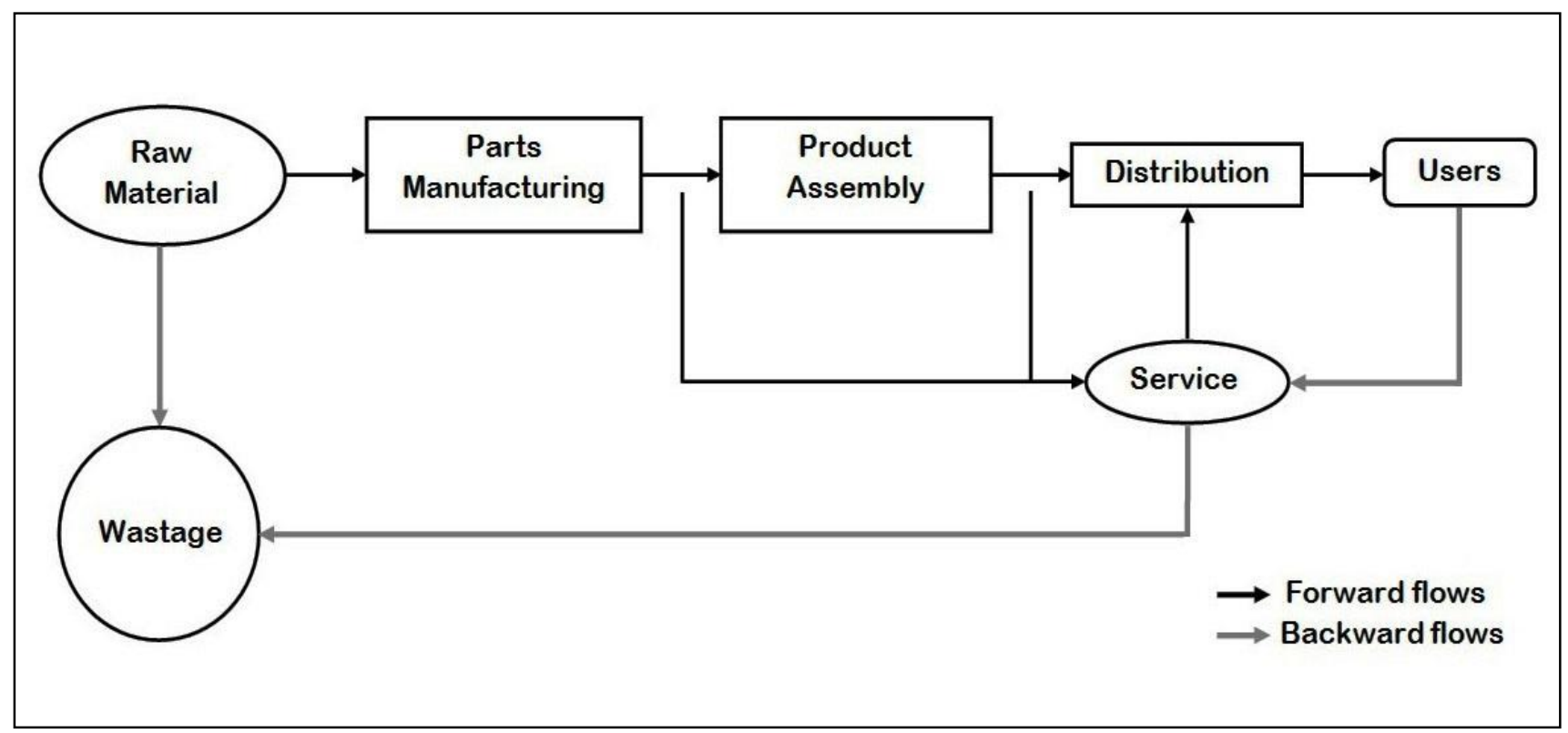

Fig. 1. Flow diagram of product recovery options

In order to perform product recovery profitable and according to applicable laws and regulations, collection of retired product must be planned. The retired product which required higher smooth surface is not significantly explored till now and therefore references available on this subject are very few. This is mainly owing to the absence of sustain research on this subject. Out of these, this chapter presents 
the current problems and challenges to recovery of mating surfaces. The chapter objective is to highlight the current conditions of recovery of the mating parts to a desired level of design intricacies.

\section{Related issues of product recovery}

The primary concern of product recovery of mating surfaces has been a deposition of new material on the worn-out or wear surfaces. The engineering parts having mating functional surfaces are exhaust valve, valve seat, gears, cylinder linear, shafts, guide block etc. Therefore, recovery of mating surface is proceed with the use of suitable metal deposition technique. There are various methods for metal deposition which includes- shield metal arc (SMA), metal inert gas (MIG), submerged arc (SA), tungsten inert gas (TIG), high velocity oxy-fuel (HVOF) and laser cladding. The basic procedure for recovery of mating surface with related issues is shown in Fig. 2.

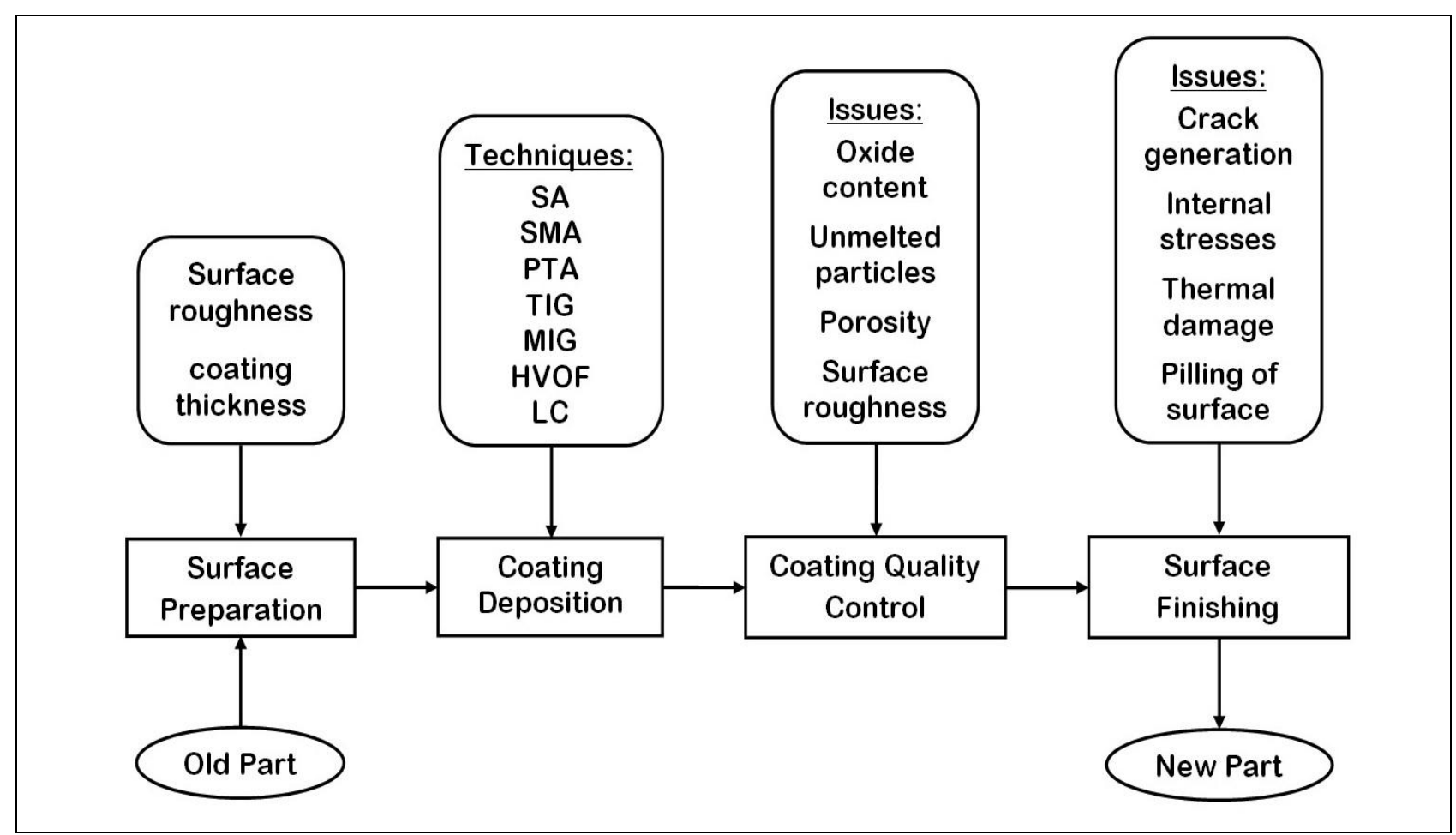

Fig. 2. Product recovery procedure with related issues for mating surfaces

Today scenario, most of deposition techniques are well maturing in terms of academic research and technological developments (Gharbi \& Qin, 2013). Hence, we can say that coating quality control related issues such as oxide content, unmelted particles, porosity, bonding strength, surface roughness etc. are controlled by using appropriate techniques and its optimum input process parameters.

The secondary concern of recovery of mating surfaces has been an achieving of high surface finishing and geometrical accuracy after metal deposition. This is the most crucial stage today and having many surface integrity issues which includes crack initiation, pilling of surfaces, swell, thermal damage, internal stresses etc. During conventional finishing methods due to the chip formation mechanism, a great 
Singh, H. \& Jain, P. K.: The Current Issues and Challenges of Product Recovery of ...

part of the produced energy is converted into heat and high temperatures are generated at the interface between the abrasive grain and the coating surface. These temperatures are the main source of damage on the machined surface (Shaw, 1984). It was found that thermal stresses generated in the grinding process were the primary cause of the tensile residual stresses (Chen \& Liang, 2000), which cause a reduction in the service life under stress corrosion or fatigue conditions. In many cases, the thermal damage of the workpiece limits the productivity of advanced grinding methods.

\section{Challenges of product recovery}

The challenges are to solve the finishing problems of deposited coating. The surface integrity problems are shown in Fig.3 (Oliveira, 2009 and Smolenska, 2010). Since the publication on this subject are small, it is relevant to understand the industrial situation regarding finishing method development. The idea is the focus on the advance hybrid finishing methods, which are able to remove small amount of material from the deposited coating with high surface finish and geometrical accuracy. Electrochemical grinding (ECG), electrochemical honing $(\mathrm{ECH})$ (Singh \& Jain, 2014) etc. will be the alternate that can provide the required output.

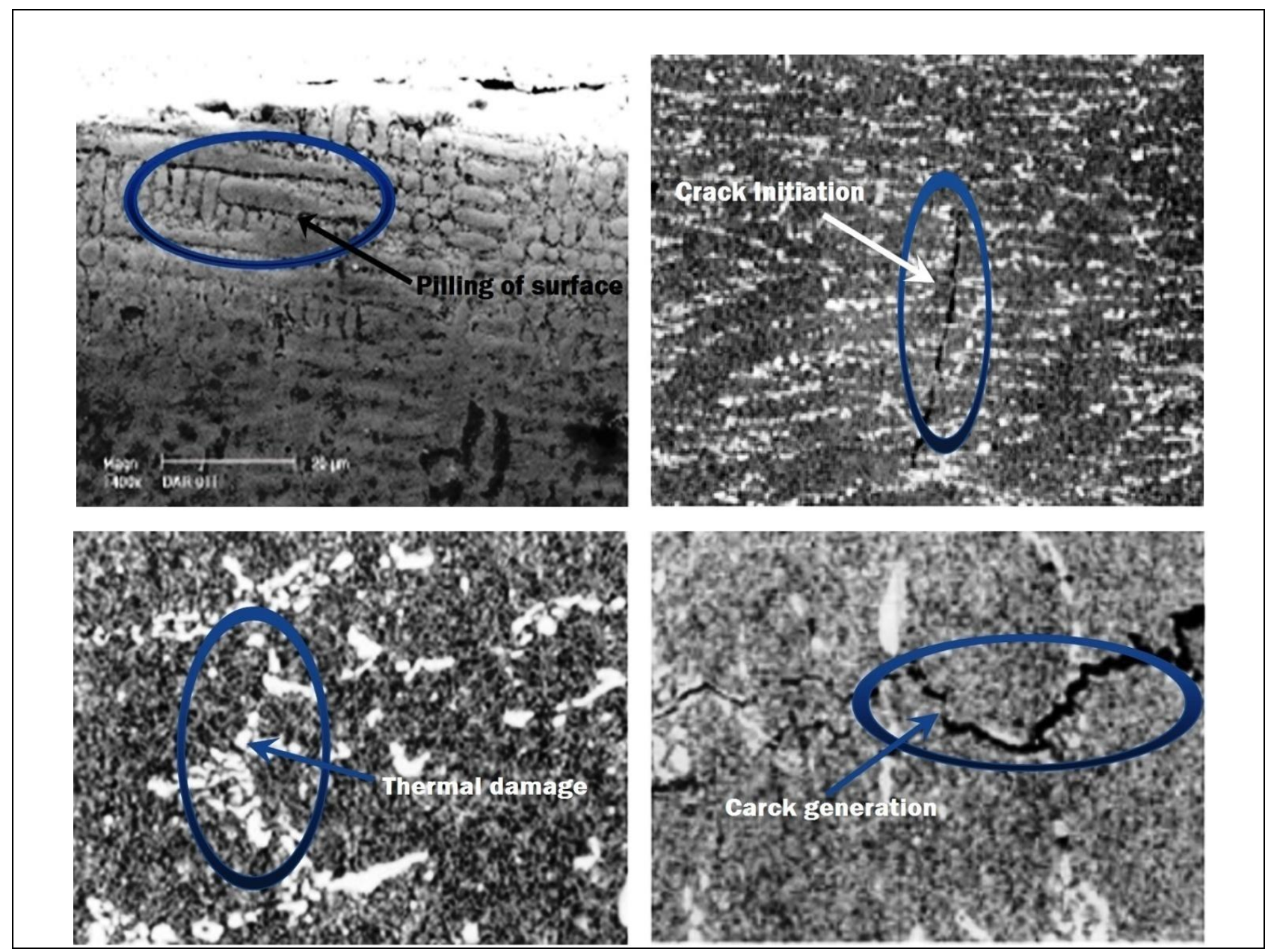

Fig. 3. Surface integrity issues with finishing processes 
Rombouts presents the poor surface finish issues, which are the one of the main limitation of laser cladding process. They showed that the use of thin additive layers, and large melt-pools improve surface finish, and that increased powder/laser interaction distances, resulting in particle melting were also beneficial factors for surface finish. They predicted $R_{a}$ value of laser cladding surface in the range of 30 to $110 \mu \mathrm{m}$. Therefore, still the coating required further finishing process to make the surface high finish, $\mathrm{R}_{\mathrm{a}} 0.5 \mu \mathrm{m}$. The hard coatings based on HVOF cladding were presented by Khanna in 2009, Table 1 shows the various properties determined for different coatings.

\begin{tabular}{|c|c|c|c|}
\hline Coatings & $\begin{array}{l}\text { Surface Roughness } \\
\qquad(\mu \mathrm{m})\end{array}$ & Surface Hardness $\left(\mathrm{HV}_{0.3}\right)$ & $\begin{array}{l}\text { Porosity } \\
(\%)\end{array}$ \\
\hline $\begin{array}{l}100 \% \\
\text { NiCrBSiFe }\end{array}$ & 9.011 & 358.7 & 2.46 \\
\hline $\begin{array}{l}15 \% \mathrm{WC} / \mathrm{Co} \\
85 \% \mathrm{NiCrBSiFe}\end{array}$ & 9.387 & 696.2 & 2.07 \\
\hline $\begin{array}{l}35 \% \mathrm{WC} / \mathrm{Co} \\
65 \% \mathrm{NiCrBSiFe}\end{array}$ & 8.467 & 747.5 & 3.94 \\
\hline $\begin{array}{l}60 \% \mathrm{WC} / \mathrm{Co} \\
40 \% \mathrm{NiCrBSiFe}\end{array}$ & 5.58 & 792 & 2.49 \\
\hline $100 \% \mathrm{WC} / \mathrm{Co}$ & 7.644 & 1003.5 & 3.79 \\
\hline
\end{tabular}

Tab. 1. A summary of various data characterized for HVOF coating (Khanna, 2009)

\section{Conclusion}

Product recovery of mating surfaces is in the preliminary stage and therefore a sustained global research is mandatory to meet the surface quality as good as of new components. The coating deposition related issues are controlled by using suitable processing conditions. Now-a-days, surface integrity issues with the finishing processes are the main concern. There is a need of vigorous investigation to properly analysed the conventional finishing process with the deposited coatings and there is possibility to introduce the advanced hybrid finishing processes to deal with the finishing problems like internal stresses, thermal damage and pilling of surface of the deposited coatings. ECH is one of the potential finishing process can be used for 
Singh, H. \& Jain, P. K.: The Current Issues and Challenges of Product Recovery of ...

remanufacturing. Product recovery based articles are introductory in nature and do not provide much analytical information about the recovery of mating surfaces.

\section{References}

Chen, X.Y. and Liang, G.Q. (2006). America remanufacturing and our study review, World Technol Study Dev, Vol. 6 (28), pp. 7-9

Gharbi, M., Peyre, P. and Gorny, C. (2013). Influence of various process conditions on surface finishes induced by the direct metal deposition laser technique on a $\mathrm{Ti}-$ 6Al-4V alloy, J. of Material Processing Technology, Vol. 213, pp. 791-800

Hua, Y., Wu, Y.W., Jiang, H.N. (2009). Overviews on the features of the remanufacturing mechanics products and the current remanufacturing technologies, Group Technol Prod Mod, Vol. 26(2), pp. 1-8

Khanna, A.S., Kumari, S., Kanungo, S. and Gasser, A. (2009). Hard coating based on thermal spray and laser cladding, J. of Refractory Metals \& Hard Materials, 27, pp. 485-491

Lindahl, M., Sundin, E., Ostlin, J. and Bjorkman, M. (2006). Concepts and definitions for product recovery: analysis and clarification of the terminology used in academia and industry, Innovation in Life Cycle Engineering and Sustainable Development, pp. 123-138, ISBN: 978-1-4020-4601-8

Ma, X.Q., Roth, J., Gandy, D.W. and Frederlck, G. L. (2006). A new high-velocity oxy fuel process for making finely structered and high bonded inconel alloy layers from liquid feedstock, J. Thermal Spray Technology, Vol. 15(4), pp.670-674

Misra, J.P., Jain, P.K. and Sevak, R. (2012) ECH of spur gear - a step towards commercialization, DAAAM International Scientific Book, pp.197-212.

Oliveira, J.F.G., Silva, E.J., Guo, C. and Hashimoto, F. (2007). Industrial challenges in grinding, CIRP Annals - Manufacturing Technology, Vol.58, pp. 663-680

Shaw, M.C. (1984). Metal cutting principles, Oxford University Press, London, pp. 594

Singh, H. and Jain, P.K. (2014). Remanufacturing with ECH - a concept, International Journal of Procedia Engineering, Vol. 69, pp.1100 - 1104

Smolenska, H. and Konczewicz, W. (2010). Failure analysis of the exhaust valve face in diesel marine engine, Advances in Materials Sciences, Vol. 10, pp. 11-18

Thierry, M., Salomon, M., Nunen, J.V. and Wassenhove, L.V. (1995). Strategic issues in product recovery management, California Management Review, Vol. 37, pp. 114-135

Zhanga, T., Chua, J., Wangb, X., Liub, X. and Cuia, P. (2011). Development pattern and enhancing system of automotive components remanufacturing industry in china, J. of Resources, Conservation and Recycling, Vol. 55, pp. 613-622

$\mathrm{Xu}$, B.S. (2007). Remanufacturing and cycle economic. Science Press, Beijing Xu, B.S., Zhu, S., Ma, S.N. (2003). Construct and development of equipment remanufacture engineering specialty, China Surface Engineering, Vol. 1, 6(3) pp.1-6 Qin, Q., and Chen, G. (2014). Effects of parameters on surface roughness of metal parts by selective laser melting, Journal of Advanced Materials Research, Vol. 834836, pp. 872-875

Zhu, K.Y. (2006). Car remanufacturing differs obviously and need time to remove, China Automobile Newspaper, Vol. 11 